\title{
Peculiarities of Atypical Meningiomas: Literature Review
}

\section{Peculiaridades dos meningiomas atípicos: Revisão da literatura}

\author{
${ }^{1}$ Department of Neuroscience, Pontifícia Universidade Católica do \\ Paraná, Londrina, Paraná, Brazil \\ ${ }^{2}$ Department of Neurosurgery, Hospital Evangélico de Londrina, \\ Londrina, Paraná, Brazil \\ ${ }^{3}$ Medical Internship, Pontifícia Universidade Católica do Paraná, \\ Londrina, Paraná, Brazil \\ ${ }^{4}$ Rehabilitation Science Program, Universidade Estadual de Londrina, \\ Londrina, Paraná, Brasil \\ ${ }^{5}$ Department of Health and Rehabilitation, Universidade Norte do \\ Paraná, Londrina, Paraná, Brazil \\ ${ }^{6}$ Neurology Residency Program, Hospital Evangélico de Londrina \\ Londrina, Brazil \\ ${ }^{7}$ Department of Neurology, Pontifícia Universidade Católica do \\ Paraná, Londrina, Paraná, Brazil
}

Rafael Rodrigues Pinheiro dos Santos ${ }^{1 *(1)}$ Ana Carla Mondek Rampazzo ${ }^{1 *(1)}$

Carlos Alexandre Martins Zicarelli2,3,4,50 Leonardo Valente de Camargo 6,7(1) Address for correspondence Rafael Rodrigues Santos, medical
student, Avenida Jockey Club, 485, 86072-360, Londrina, Paraná,
Brazil (e-mail: rafaelsdpr@gmail.com; anamondek35@gmail.com).

Arq Bras Neurocir 2022;41(2):e137-e144.

\begin{abstract}
Keywords

- meningioma

- malign meningioma

- immunohistochemistry

- prognosis

Introduction Meningiomas are common tumors of the central nervous system that represent around $30 \%$ of primary tumors. However, the incidence of atypical meningiomas (AMs) is lower, of approximately $15 \%$ of all meningiomas, and they present high rates of relapse and mortality.

Aim To review peculiarities of AMs.

Methodology A literature review of articles published in English between 2009 and 2020 on the PubMed and Biblioteca Virtual em Saúde (BVS) databases using the terms meningioma and atypical.

Results Atypical meningiomas are rare and more prevalent in older males. The clinical condition depends on the site of the tumor, and a definitive diagnosis of AM is only possible via anatomical pathology. Moreover, prominent studies have indicated a relationship between the presence of the anti-Ki67 antibody/mindbomb ( $\left.K_{i}-67 / M I B 1\right)$ marker as an aid in the definition of AM and one of the determinants of tumor aggressiveness. Imaging studies have also advanced in terms of seeking criteria using magnetic resonance that may suggest the malignancy of a lesion. As far as treatment is concerned, total resection remains the main therapeutic option, and it has a direct relationship with survival and time until disease progression. Lastly, there are many factors involved in the prognosis of AM.
\end{abstract}

* Authors with the same contribution to the article.

received

February 3, 2021

accepted

DOI https://doi.org/

10.1055/s-0042-1742427. ISSN 0103-5355. (c) 2022. Sociedade Brasileira de Neurocirurgia. All rights reserved. This is an open access article published by Thieme under the terms of the Creative Commons Attribution-NonDerivative-NonCommercial-License, permitting copying and reproduction so long as the original work is given appropriate credit. Contents may not be used for commercial purposes, or adapted, remixed, transformed or built upon. (https://creativecommons.org/ licenses/by-nc-nd/4.0/)

Thieme Revinter Publicações Ltda., Rua do Matoso 170, Rio de Janeiro, RJ, CEP 20270-135, Brazil 


\section{Resumo}

\section{Palavras-chave \\ - meningioma \\ - meningioma maligno \\ - imuno- histoquímica \\ - prognóstico}

Conclusion Atypical meningiomas continue to be a challenge, requiring further and more specific studies to provide a better understanding of it.

Introdução Os meningiomas são tumores comuns do sistema nervoso central, representando cerca de 30\% dos tumores primários. Contudo, a incidência de meningiomas atípicos (MA) é menor, cerca de 15\% do total dos meningiomas, e eles apresentam altas taxas de recidiva e mortalidade.

Metodologia Revisão da literatura, nas bases de dados PubMed e Biblioteca Virtual em Saúde (BVS), utilizando os termos "meningioma" e "atypical", publicados em língua inglesa entre 2009 e 2020.

Objetivo Revisar as particularidades dos MA.

Resultados MA são raros, mais prevalentes em homens de idade avançada. O quadro clínico depende da localização do tumor e o diagnóstico definitivo de MA só se dá por meio do anatomopatológico. Ademais, estudos importantes têm apontado para a relação da presença do marcador anticorpo monoclonal/mindbomb (Ki-67/MIB1) como auxiliador na definição de MA e um dos determinantes de agressividade tumoral. Os estudos de imagem também avançam no sentido de buscar critérios na ressonância magnética que possam sugerir a malignidade de uma lesão. Em relação ao tratamento, a cirurgia de ressecção total se mantém como principal terapêutica, com relação direta na sobrevida e no tempo livre de progressão de doença. Por fim, o prognóstico em MA é multifatorial.

Conclusão MA continuam como um desafio, necessitando de mais estudos específicos para compreendê-los melhor.

\section{Introduction}

The original definition of meningioma was coined in 1922 by Harvey Cushing, who described it as a tumor originating in the meninges, in both the brain and the spinal cord. ${ }^{1}$ According to the definition, these tumors originate from cells in the arachnoid meninge. $^{2}$

Their incidence shows that they are common tumors of the central nervous system (CNS) originating in the meninge, in particular the arachnoid, and are usually benign and one-off. ${ }^{3,4}$ This type of lesion equates to around $30 \%$ of all primary tumors of the CNS, and it typically occurs in older individuals, for whom the incidence is of approximately 6 per 100 thousand. ${ }^{3,5}$

According to the 2016 classification by the World Health Organization (WHO), there are three different grades of meningioma, namely: benign meningioma (grade I), atypical meningioma (AM, grade II), and anaplastic meningioma (grade III). ${ }^{6}$ Grade I accounts for $80 \%$ to $92 \%$ of the cases, while grade II represents $4.2 \%$ to $15 \%$ of all meningiomas, and grade III, $1 \%$ to $3 \%$. $5,7,8$

Grade-II meningiomas are characterized by high rates of mitosis, accompanied by cell necrosis, hypercellularity, structural changes to the cells, in addition to leading to invasion of the adjacent tissue. ${ }^{2,7}$ They also present a $40 \%$ recurrence rate within 5 years of total resection, and a high rate of mortality when compared with grade-I meningiomas. ${ }^{6,7}$

In addition to a histological evaluation, immunohistochemistry is of paramout importance in the evaluation of AMs and anaplastic meningiomas, particularly the following markers: the epithelial membrane antigen, the MIB-1 antibody, and the cell proliferation marker anti- $\mathrm{K}_{\mathrm{i}} 67$ antibody $\left(\mathrm{K}_{\mathrm{i}}-67\right){ }^{7}$ The present study intends to provide a broad, updated review of the literature concerning the peculiarities of AMs.

\section{Methodology}

\section{Imaging}

The present study used the imaging scans of a patient with an AM cared for in Clinic N3 and operated on at the neurosurgery services of Hospital Evangélico de Londrina, state of Paraná, Brazil by one of the authors (CAMZ). Permission for the use of the images was acquired through a Free and Informed Consent Agreement, which was understood and signed by the patient.

\section{Literature Review}

The literature review of articles published between 2009 and 2020 was conducted on the PubMed and Biblioteca Virtual em Saúde (BVS) databases.

The descriptors used were meningioma and atypical. The inclusion criteria were: the explicit mention of the words atypical meningioma or WHO grade-II meningioma, articles published in journals with an impact factor greater than 1 , and studies in English. The following articles were excluded: those relating to pediatric meningiomas, those concerning 
syndromes that mimic meningiomas, and case reports, editorials, ideas and opinions. Access to the articles was gained via the periodical platform of Coordenação de Aperfeiçoamento de Pessoal de Nível Superior (CAPES). ${ }^{a}$

\section{Results}

\section{Epidemiology}

Meningiomas are responsible for more than $30 \%$ of CNS tumors, with an incidence between 4.4 and 6 per 100 thousand inhabitants, and AMs consitute $4.2 \%$ to $15 \%$ of the cases. ${ }^{9-11}$ In general, meningiomas are more common in women aged between 50 and 60 years; however, WHO grade-II meningiomas are more prevalent in older males, usually between 60 and 70 years of age. ${ }^{8,9,12}$ This epidemiological difference seems to be explained by the influence of estrogen in the pathogenicity of WHO grade-I meningiomas, which does not occur with grade-II or grade-III meningiomas. ${ }^{10}$ The average rate of incidence of meningiomas in the United States was higher than 25 thousand cases a year between 2008 and 2012, a consequence of the greater access to imaging examinations and the aging of the population, leading to an increase of 3.9 times since $1943 .^{13,14}$ The chance of developing this type of lesion, in the absence of risk factors, is of $\sim 1 \% .{ }^{13}$ Metastasis is extremely rare, occurring in $0.1 \%$ of cases, mainly affecting the lungs and liver, and as many as $3 \%$ of WHO grade-II meningiomas evolve into grade III. ${ }^{12,15}$

\section{Clinical Condition and Site of the AM}

The clinical presentation of meningiomas depends on the site affected, commonly associated with cephalea secondary to tumor growth, focal neurological deficit, convulsions directly or indirectly associated with the tumor, and changes in vision and behavior. ${ }^{12,13}$ The case studies presented by Gyawali et al. ${ }^{16}$ demonstrate that one of the more common sites for the development of meningiomas, in general, is the frontal lobe, and patients may develop psychiatric symptoms such as severe depression and, in more serious cases, Godot syndrome, which is characterized by the association of accentuated symptoms of anxiety and dementia. Obsessive symptoms are more frequently linked to lesions situated in the left frontal lobe, while the involvement of the right frontal lobe is more commonly related to bipolar disorders, alcohol abuse, and visual and auditory hallucinations. ${ }^{16} \mathrm{~A}$ short while after, another study ${ }^{13}$ demonstrated that the most common site of intracranial and juxtacrine meningiomas is the convexity (lateral area of the hemispheres), corresponding to $20 \%$ to $34 \%$ of cases, while the frontobasal lesions are ranked in fourth position, accounting for around $10 \%$ of the cases; therefore, the clinical presentation depends on the site of the lesion.

\footnotetext{
a A foundation within the Brazilian Ministry of Education whose central purpose is to coordinate efforts to improve the quality of Brazil's faculty and staff in higher education through grant programs.
}

AMs present with a slightly different behavior. The most common location is also in the convexity, it corresponds to around $57 \%$ of the cases, followed by the cerebral sickle (12\%), the posterior fossa (10\%), frontobasal (6\%), the sphenoid wing (4\%), the parasagittal (4\%), the tentorial (4\%), the cavernous sinus (2\%), and other sites that correspond to around $1 \%$ of the cases (tuberculum sellae, orbital sphenoid, and orbit). ${ }^{17}$ The lesions at the base of the skull is an independent risk factor for WHO grade-II and grade-III tumors. $^{18}$

\section{Anatomical Pathology}

The diagnosis of meningiomas is still established through an anatomo-pathological analysis of the resected tumor. 8,10 According to the 2016 WHO classification, atypical meningiomas are characterized by the presence of at least three of the following histological changes: 1) spontaneous necrosis; 2) loss of architectural structure; 3 ) prominent nucleus; 4) hypercellularity; and 5) small cells or the presence of cerebral invasion with 4 or more mitosis per field. Accordingly, the rate of mitosis per field may be used to differentiate between an atypical lesion and an anaplastic lesion, and this is because meningiomas with more than 20 mitoses per 10 high-power fields are classified as WHO grade-III, while rates between 4 and 19 mitoses remain in the WHO grade-II spectrum. ${ }^{13}$ Goés et al., ${ }^{20}$ in a case study involving 106 patients, evaluated spontaneous necrosis present in WHO grade-I and grade-II tumors, and concluded that those patients suffering from AM with evidence of spontaneous necrosis present a 4.2-time higher risk of recurrence compared with patients without this histological characteristic. Moreover, a recent systematic review with meta-analysis ${ }^{21}$ demonstrated that, for every increase of 1 mitosis per 10 high-power fields, the risk of recurrence of AM goes up $20 \%$.

Besides the microscopic characteristics, the immunohistochemical analysis has great diagnostic and prognostic value regarding WHO grade-II meningiomas. ${ }^{8,10}$ Several studies have indicated that, in addition to the presence of epithelial membrane antigen (EMA) and negativity for protein $S-100$ (also present in grade-I meningiomas), the positivity of marker $K_{i}-67 / M I B-1$ may be useful for differentiating between AMs and other subtypes. ${ }^{8}$ The presence of this marker is directly related to the more aggressive behavior of this subtype. $^{8,22}$ The systematic review with meta-analysis conducted by Liu et al. ${ }^{22}$ (2020), demonstrated that the high expression of $K_{i}-67$ ( $>4 \%$ ) is linked to worse overall survival, greater disease progression, and higher rates of recurrence of the tumor.

The $K_{i}-67$ marker may be positive in around $7.2 \%$ of patients with AMs; moreover, the male gender may be considered an independent risk factor for high rates of $K_{i-}$ 67 positivity. Tumors at the base of the skull usually present a low $K_{i}-67$ index. ${ }^{16}$ Progesterone receptors are less prominent in grade-II meningiomas and may have an inverse relationship with $K_{i}-67$ rates. $^{18}$

Bromodeoxyuridine $(B r d U)$ has a close relationship with the rates of tumor recurrence: when greater than 5\%, a $100 \%$ probability of recurrence is denoted; moreover, the high 
expression of fatty acid synthase (FAS) and brain fatty acidbinding protein (BFABP) is associated with invasion of the adjacent tissue by the tumor and an increased chance of recurrence. $^{18}$

Around $71.4 \%$ of WHO grade-II tumors present an overexpression of CD163, and this is associated with the accelerated growth of the tumor and, in other types of cancer, with a bad prognosis. ${ }^{23}$

\section{Genetic, Epigenetic and Molecular Alterations}

High-grade meningiomas, like AMs, have been shown to have high cytogenetic and molecular complexity, with activation of oncogenes, inactivation of tumor-suppressor genes, and alterations to other genes involved in various molecular pathways. ${ }^{9}$ In this regard, these neoplasias present a higher expression of patched 1 (PTCH1) messenger ribonucleic acid ( $m R N A$, an important receptor protein), aberrant methylation of tissue inhibitor of metalloproteinase 3 gene (TIMP3), aberrant methylation of WNK lysine deficient protein kinase 2 (WNK2), high levels of microRNA-21 (miR-21), as well as anomalous signaling through proteins of the insulin-like growth factor (IGF) family. ${ }^{9}$ In general, these alterations are related to greater progression, increased tumorigenicity, and to a higher rate of recurrence of grade-II and -III meningiomas. ${ }^{9}$ Moreover, AMs may be generated by mutations in particular genes, such as a loss of $6 q, 9 p, 10 q$ and $14 q$, as well as expansion in $17 q$. There are also rare cases in which gradeII meningiomas develop due to mutations in tumor-suppressor genes such as TP53 and/or deletion of the cyclin-dependent kinase inhibitor $2 A(C D K N 2 A)$ gene. ${ }^{8,9}$

The association of mutations in the neurofibromin 2 (NF2) gene with meningioma is well documented; moreover, there is a predilection for this mutation when linked to losses in chromosomes $22 q$ and $1 p$ in WHO grade-I lesions, present in around $50 \%$ of cases. ${ }^{24}$ This genetic pattern is associated with patients diagnosed with AM with an average age of 60 years, more common in men and less frequently afflicting the base of the skull. ${ }^{24}$

\section{Imaging Examination}

With regard to the radiology of AMs, recent studies point to certain characteristics in magnetic resonance imaging (MRI) that may indicate high-grade meningiomas. ${ }^{10,25}$ In this regard, the case series by Tan et al. ${ }^{25}$ (2015) demonstrated that the points that differentiate WHO grade-I meningiomas from grades II and III are: increased perfusion (mean cerebral blood volume), high-value tensor diffusion imaging (anisotropic fraction), spectroscopy with increased choline/creatine ($\mathrm{Cho} / \mathrm{Cr}$ ), and the presence of lactate. Other characteristics that point to atypia of the meningioma are areas of hypodense tumor and margins indicative of cerebral invasion. ${ }^{9}$

Recently, studies have shown that there are semantic, radiomic values in MRI that may be able to predict AM recurrence. In this regard, Darius Kalasauskas et al. ${ }^{26}$ (2020), in a cohort study comprising 76 patients with an average follow-up of 41.6 months, identified that the presence of a cystic component in AM was associated with a worse prognosis and shorter time until recurrence $(p<0.001)$.

Examples of AM can be seen in - Figs. 1 and $\mathbf{2}$.

\section{Surgery}

Surgery is the main treatment for meningiomas, as it enables the histopathological classification and exerts an important influence on the time until recurrence. ${ }^{8,10,12,21,26}$ The aims of surgery and Simpson resection grades are the same as those for WHO grade-I meningiomas and other meningioma subtypes. ${ }^{10,21,27}$ Simpson grade-I surgical resection is the technique with the highest margin of safety, which involves complete resection of the tumor, with a healthy margin of dura mater and of the affected bone. ${ }^{10}$ The use of this technique is linked to greater patient survival and a longer recurrence-free time. ${ }^{27}$ Nevertheless, there are situations in
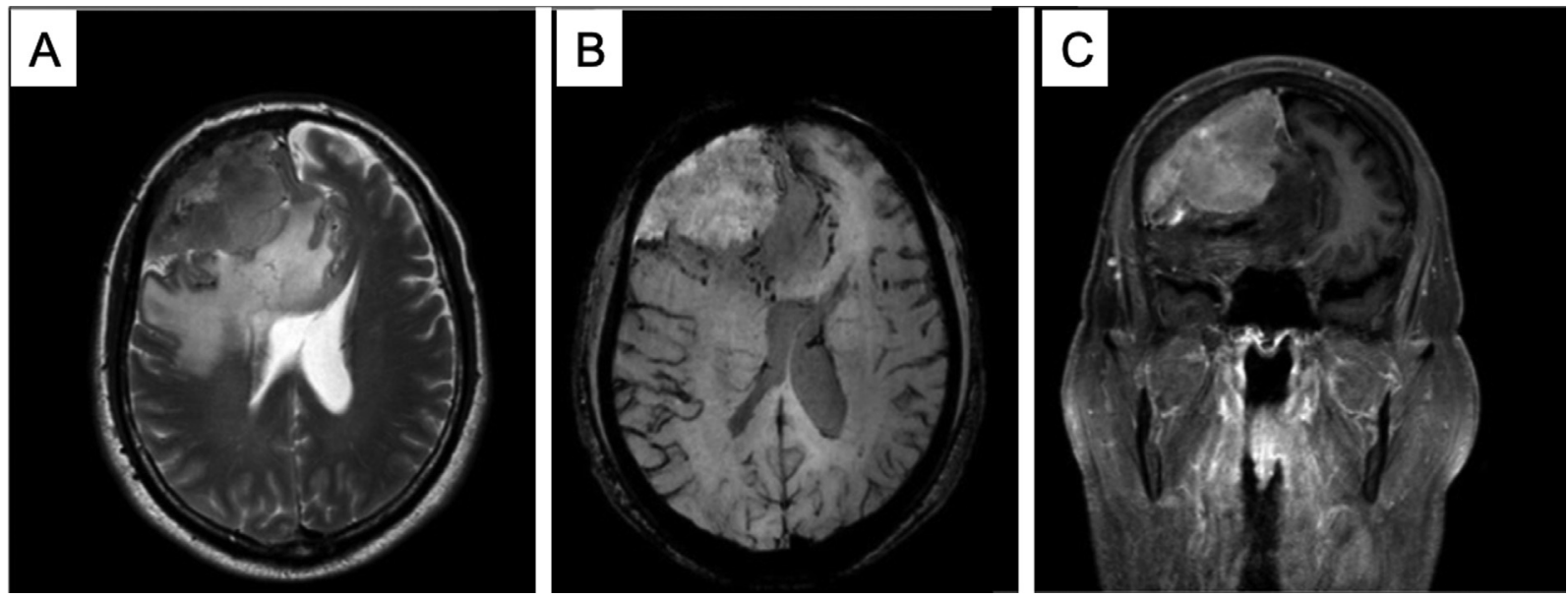

Fig. 1 Axial section of a T2-weigthed magnetic resonance imaging (MRI) scan (A) and fluid-attenuated inversion recovery (FLAIR) (B), and coronal section $(C)$ demonstrating an expansive lesion measuring $7.4 \times 7.3 \times 4.2 \mathrm{~cm}$ (latero-lateral (LL) $\mathrm{x}$ antero-posterior (AP) $\mathrm{x}$ craniocaudal (CC)), particularly extra-axial in the right frontal region, with signs of dural implantation in the inner table of the frontal right bone and contact with the interhemispheric falx and upper sagittal sinus (anterior region). The lesion presents an extensive area with hypersignal in T2/FLAIR in the adjacent parenchyma, suggesting edema. Mass effect is evidenced through the deviation of the midline to the left, as well as obliteration of grooves and descending transtentorial uncal herniation. 


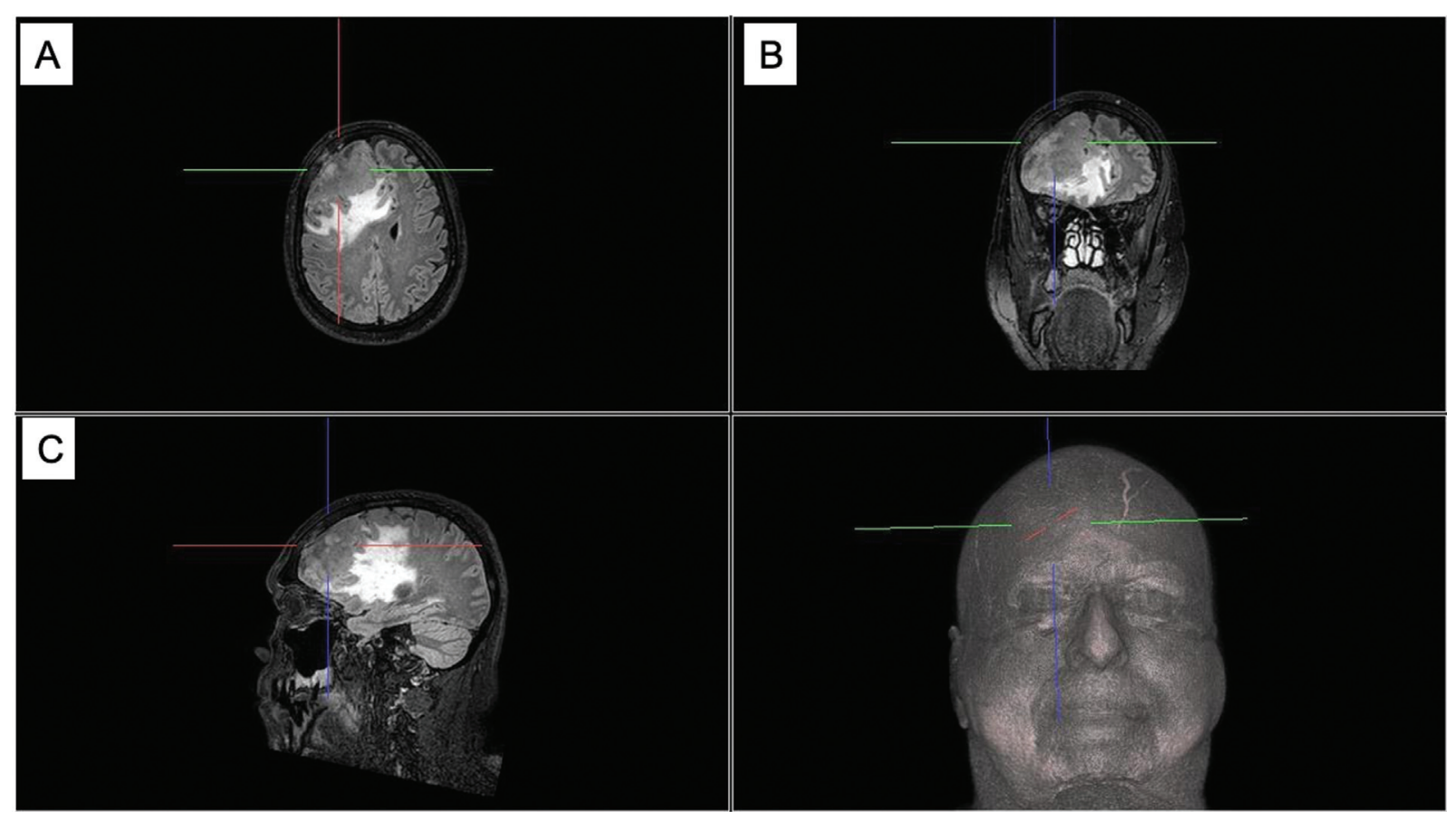

Fig. 2 Encephalon MRI. Axial (A), coronal (B) and sagittal (C) sections in FLAIR demonstrating an atypical meningioma with an emphasis on tumor infiltration.

which this technique cannot be used, depending on the site and the degree of invasion in the cerebral parenchyma. ${ }^{10,27}$ In this regard, the other Simpson resection grades that may be used are: grade II (complete macroscopic resection with coagulation of the dural attachment); grade III (macroscopic resection of the tumor without resection of the affected dura mater or bone); grade IV (partial resection); and grade $\mathrm{V}$ (biopsy). It is important to stress that the extent of tumor resection is recognized as the main predictor of survival in patients with meningiomas. $8,10,12,21,26-28$

Meningiomas are generally vascularized and, in cases in which hypervascularization is identified, or when it is supposed that it will be possible to rapidly control the bleeding during the surgical procedure, this may be preceded by prior embolization of the tumor. ${ }^{10}$ In these cases, an embolic liquid is normally used, such as ethylene vinyl-alcohol (EVOH) copolymer, with the aim of facilitating the surgical procedure. ${ }^{10}$

Surgical planning and postoperative control are as important as the surgical procedure itself ( $\mathbf{- F i g s . ~} 3$ and $\mathbf{4}$ ).

\section{Associated Treatment}

There are differences of opinion about the benefits and the harm caused by adjunct radiotherapy (RT) after the partial and total resection of the AM. ${ }^{3,10,29}$ Many studies $3,27,29$ demonstrate that RT after total resection of the tumor is not relevant for the local control of recurrence and for the survival of the patient. Meanwhile, other articles indicate ${ }^{3,10,30}$ an important benefit when said adjunct therapy is used. The types of RT that can be employed are stereotaxic radiosurgery and fractionated external beam $\mathrm{RT}^{3}$

Due to the aggressive behavior of these meningiomas, the use of drug therapy may be necessary. In this regard, recent studies ${ }^{10,31}$ have pointed to the efficacy of hydroxyurea in cases of incomplete AM resection in relation to the increase in progression-free survival when compared with the conservative treatment. Other studies ${ }^{32}$ show success with the use of bevacizumab (Avastin, Genentech, South San Francisco, CA, United States), a monoclonal antibody that blocks the action of vascular endothelial growth factor (VEGF), precluding the growth of blood vessels that feed malignant tumors, for the treatment of refractory AMs. It should be stressed that, with meningiomas, there was no significant efficacy of the classic chemotherapy agents like temozolomide, irinotecan, doxorubicin and ifosfamide. ${ }^{27}$

\section{Prognosis}

As far as AM is concerned, after total resection, the rate of recurrence is of $\sim 40 \%$, and survival is of $\sim 11.8$ years. ${ }^{11,19}$ of the prognosis markers, $K_{i}-67$ is related to the rate of survival, and patients who present $K_{i}-67<10 \%$ have a $60 \%$ higher rate of survival when compared with patients with $K_{i}-67>10 \%{ }^{33}$ Another factor related to the increase in AM patient survival is being under 60 years of age, and undergoing Simpson grade I resection ( $p=0.055)$. Radiotherapy and adjuvant chemotherapy did not show statistical significance in terms of the increase in the survival of these patients. ${ }^{33}$ In general, atypical lesions are associated with a longer time to disease progression (TDP), when compared with anaplastic lesions. In 2009, Durand et al. ${ }^{33}$ suggested that patients submitted to postoperative RT presented a shorter TDP when compared with those who did not undergo RT. In cases in which a subtotal or partial resection is performed, there appears to be consensus as to the indication of postoperative RT, while in patients submitted to total resection of the lesion with tumor recurrence, reoperation is preferable due to high mortality rates of AMs, as recurrent AMs present an increased risk of mortality. ${ }^{34}$ 

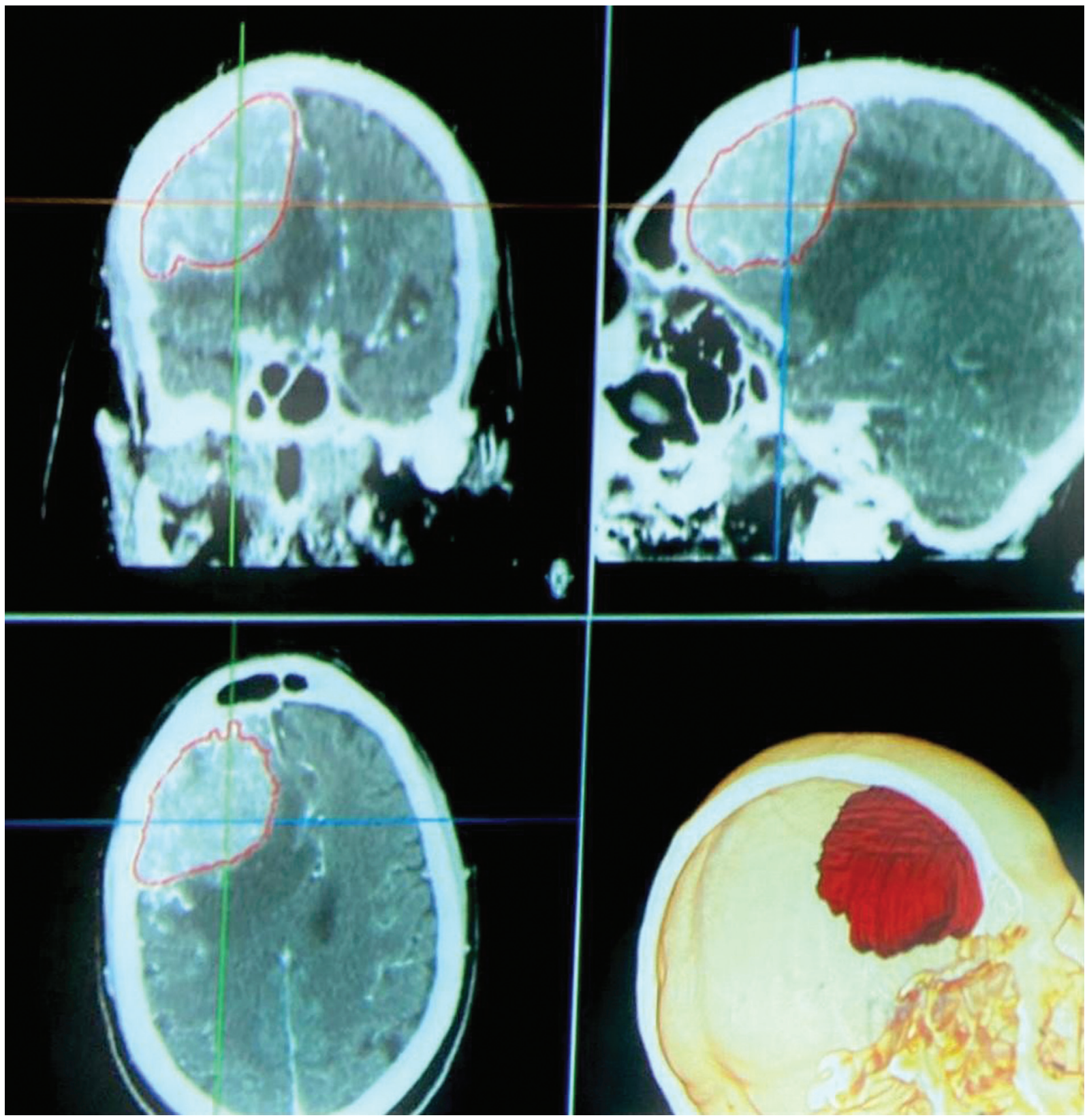

Fig. 3 Image of the neuronavigation for surgical planning.
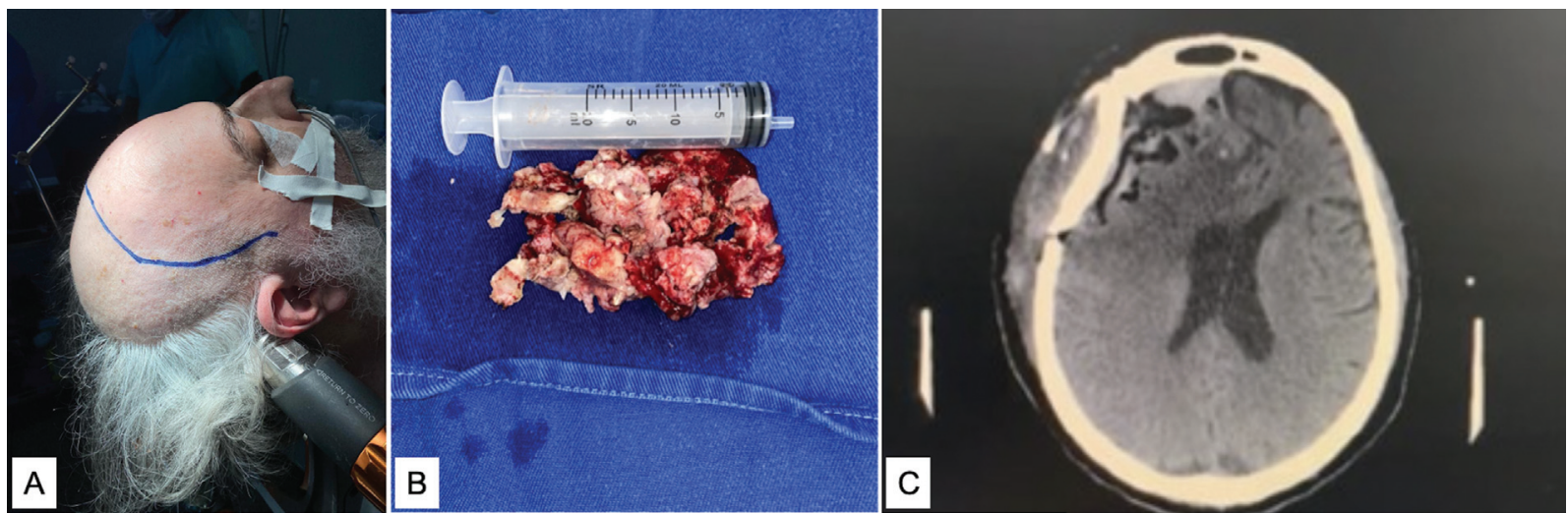

Fig. 4 Patient positioned with Mayfield skull clamp (A). Macroscopic view of the tumor (B). Postoperative computed tomography scan of sthe kull demonstrating total resection of the tumor (Simpson grade I) with cranial reconstruction with bone cement (C). 
Metastasis is rare. The cohort study by Williams et al., who evaluated a group of meningioma patients of all grades, emphasized the recurrence of metastasis mainly in gradeII lesions (16/441), and it seems to be associated with genetic alterations related for the most part to NF2, in addition to cyclin-dependent kinase inhibitor 2A (CDKN2A), BRCA1 associated protein-1 (BAP1), telomerase reverse transcriptase promoter (TERTp). ${ }^{24}$

Lastly, Chen et al. ${ }^{28}$ (2020) indicated, in a cohort study, that preoperative blood tests can help predict the prognosis of patients with AM, as they observed a significant association between the pre-operative score of the fibrinogen and neutrophil-lymphocyte ratio (F-NLR) biomarker and a recurrence of the tumor within three years. The group who presented with high levels of hyperfibrinogenemia and a high neutrophil-lymphocyte ratio had a recurrence earlier (median: 29.79 months), when compared with the groups who presented low levels of fibrinogen or a low neutrophillymphocyte ratio. ${ }^{28}$

\section{Final Considerations}

In this literature review, we sought to clarify the peculiarities of atypical meningiomas, in order to facilitate the diagnosis and follow-up of these patients.

In this context, AMs have peculiar characteristics in comparison with WHO grade-I meningiomas, such as the increased prevalence in men, the more aggressive treatment of the tumor, and the therapeutic limitation, with surgery being the only treatment offering well-established efficacy. Moreover, although several publications ${ }^{10,19,25}$ have highlighted that imaging may present characteristics which help differentiate the grades of meningioma, the histopathological analysis is still the definitive way to classify them, in addition to supplying material for molecular, histochemical and immunohistochemical tests.

Despite these limitations, the present study summarizes the scientific advances in the field of AM, which are mainly related to the prognosis of the disease. In this regard, it is worth mentioning the importance of the $K_{i}-67 / M I B 1$ marker, and genetic, molecular and histological developments, as well as the imaging findings that serve as adjunct tools to predict the chances of recurrence of the tumor and survival of the patient. Moreover, with regard to the adjunct therapy, consensus is also needed concerning the real benefits and harms of RT in atypical meningiomas, as well as the efficacy of hydroxyurea and bevacizumab. We would like to highlight the importance of presurgical embolization in selected cases. In any case, AM remains a challenge within neuro-oncology and neurosurgery, requiring further studies.

\section{Conflict of Interests}

The authors have no conflict of interests to declare.

\section{References}

1 Cushing H. The meningiomas (dural endotheliomas): Their source, and favoured seats of origin. Brain 1922;45(02):282-316
2 Baldi I, Engelhardt J, Bonnet C, Bauchet L, Berteaud E, Grüber A, Loiseau H. Epidemiology of meningiomas. Neurochirurgie 2018 Mar;64(01):5-14. Doi: 10.1016/j.neuchi.2014.05.006

3 Rogers L, Barani I, Chamberlain M, et al. Meningiomas: knowledge base, treatment outcomes, and uncertainties. A RANO review. J Neurosurg 2015;122(01):4-23

4 Koech F, Orege J, Ndiangui F, Macharia B, Mbaruku N. Multiple intracranial meningiomas: a review of the literature and a case report. Case Rep Surg 2013;2013:131962

5 Jamilson Araújo Pereira B, Nogueira de Almeida A, Henrique Pires de Aguiar P, Silva Paiva W, Jacobsen Teixeira M, Kazue Nagahashi Marie S. Comprehensive analysis of meningioma in the first two decades of life: A systematic review. Neurochirurgie 2020;66(01): 36-40. Doi: 10.1016/j.neuchi.2019.10.007

6 Gökalp HZ, Arasil E, Erdoğan A, Egemen N, Naderi S. Multiple intracranial meningiomas. Neurochirurgia (Stuttg) 1992;35(03): 95-96

7 Riemenschneider MJ, Perry A, Reifenberger G. Histological classification and molecular genetics of meningiomas. Lancet Neurol 2006 Dec;5(12):1045-1054. Doi: 10.1016/S1474-4422(06) 70625-1. Erratum in: Lancet Neurol. 2007 Feb;6(2):105

8 Andric M, Dixit S, Dubey A, Jessup P, Hunn A. Atypical meningiomas-a case series. Clin Neurol Neurosurg 2012;114(06):699-702

9 Galani V, Lampri E, Varouktsi A, Alexiou G, Mitselou A, Kyritsis AP. Genetic and epigenetic alterations in meningiomas. Clin Neurol Neurosurg 2017;158:119-125. Doi: 10.1016/j.clineuro.2017.05.002

10 Buttrick S, Shah AH, Komotar RJ, Ivan ME. Management of Atypical and Anaplastic Meningiomas. Neurosurg Clin N Am 2016;27(02): 239-247 cited2020Nov19. Doi: 10.1016/j.nec.2015.11.003

11 Fathalla H, Tawab MGA, El-Fiki A, El-Fiki A. Extent of Hyperostotic Bone Resection in Convexity Meningioma to Achieve Pathologically Free Margins. J Korean Neurosurg Soc 2020;63(06):821-826 cited2020Nov19 Doi: $10.3340 /$ jkns.2020.0020pISSN20053711eISSN1598-7876

12 Ahsan SA, Chendeb K, Profyris C, Teo C, Sughrue ME. Pharmacotherapeutic options for atypical meningiomas. Expert Opin Pharmacother 2019;20(15):1831-1836

13 Huntoon K, Toland AMS, Dahiya S. Meningioma: A Review of Clinicopathological and Molecular Aspects. Front Oncol 2020;10 (October):579599

14 Hwang KL, Hwang WL, Bussière MR, Shih HA. The role of radiotherapy in the management of high-grade meningiomas. Linchuang Zhongliuxue Zazhi 2017;6(Suppl 1):S5

15 Kessler RA, Garzon-Muvdi T, Yang W, et al. Metastatic Atypical and Anaplastic Meningioma: A Case Series and Review of the Literature. World Neurosurg 2017;101:47-56

16 Gyawali S, Sharma P, Mahapatra A. Meningioma and psychiatric symptoms: An individual patient data analysis. Asian J Psychiatr 2019;42:94-103. Doi: 10.1016/j.ajp.2019.03.029

17 Ressel A, Fichte S, Brodhun M, Rosahl SK, Gerlach R. WHO grade of intracranial meningiomas differs with respect to patient's age, location, tumor size and peritumoral edema. J Neurooncol 2019; 145(02):277-286

18 Shibuya M. Pathology and molecular genetics of meningioma: recent advances. Neurol Med Chir (Tokyo) 2015;55(01):14-27. Doi: 10.2176/nmc.ra.2014-0233

19 Louis DN, Perry A, Reifenberger G, von Deimling A, FigarellaBranger D, Cavenee WK, Ohgaki H, Wiestler OD, Kleihues P, Ellison DW. The 2016 World Health Organization Classification of Tumors of the Central Nervous System: a summary. Acta Neuropathol 2016 Jun;131(06):803-820. Doi: 10.1007/s00401-0161545-1

20 Góes P, Santos BFO, Suzuki FS, et al. Necrosis is a consistent factor to recurrence of meningiomas: should it be a stand-alone grading criterion for grade II meningioma? J Neurooncol 2018;137(02): $331-336$ 
21 Domingo RA, Tripathi S, Vivas-Buitrago T, Lu VM, Chaichana KL, Quiñones-Hinojosa A. Mitotic Index and Progression-Free Survival in Atypical Meningiomas. World Neurosurg 2020;142:191-196

22 Liu N, Song S-Y, Jiang J-B, Wang T-J, Yan C-X. The prognostic role of Ki-67/MIB-1 in meningioma: A systematic review with metaanalysis. Medicine (Baltimore) 2020;99(09):e18644. Doi: 10.1097/MD.0000000000018644

23 Kanno H, Nishihara H, Wang L, et al. Expression of CD163 prevents apoptosis through the production of granulocyte colony-stimulating factor in meningioma. Neuro-oncol 2013;15(07):853-864 https://academic.oup.com/neuro-oncology/article/15/7/853/ 1042498

24 Williams EA, Santagata S, Wakimoto H, Shankar GM, Barker FG 2nd, Sharaf R, Reddy A, Spear P, Alexander BM, Ross JS, Brastianos PK, Cahill DP, Ramkissoon SH, Juratli TA. Distinct genomic subclasses of high-grade/progressive meningiomas: NF2-associated, NF2-exclusive, and NF2-agnostic. Acta Neuropathol Commun 2020 Oct 21;8(01):171. Doi: 10.1186/s40478-020-01040-2

25 Tan LA, Boco T, Johnson AK, et al. Magnetic resonance imaging characteristics of typical and atypical/anaplastic meningiomas Case series and literature review. Br J Neurosurg 2015;29(01): 77-81

26 Kalasauskas D, Kronfeld A, Renovanz M, et al. Identification of high-risk atypical meningiomas according to semantic and radiomic features. Cancers (Basel) 2020;12(10):1-11
27 Apra C, Peyre M, Kalamarides M. Current treatment options for meningioma. Expert Rev Neurother 2018;18(03):241-249

28 Chen X, Wang G, Zhang J, et al. A Novel Scoring System Based on Preoperative Routine Blood Test in Predicting Prognosis of Atypical Meningioma. Front Oncol 2020;10(September):1705

29 Zhu H, Bi WL, Aizer A, et al. Efficacy of adjuvant radiotherapy for atypical and anaplastic meningioma. Cancer Med 2019;8(01): $13-20$

30 Aizer AA, Arvold ND, Catalano P, et al. Adjuvant radiation therapy, local recurrence, and the need for salvage therapy in atypical meningioma. Neuro-oncol 2014;16(11):1547-1553

$31 \mathrm{Kim}$ J, Kim KH, Kim YZ. The Clinical Outcome of Hydroxyurea Chemotherapy after Incomplete Resection of Atypical Meningiomas. Brain Tumor Res Treat 2017;5(02):77-86. Doi: 10.14791/ btrt.2017.5.2.77

32 Dasanu CA, Alvarez-Argote J, Limonadi FM, Codreanu I. Bevacizumab in refractory higher-grade and atypical meningioma: the current state of affairs. Expert Opin Biol Ther 2019;19(02): 99-104

33 Durand A, Labrousse F, Jouvet A, et al. WHO grade II and III meningiomas: a study of prognostic factors. J Neurooncol 2009; 95(03):367-375

34 Rogers L, Gilbert M, Vogelbaum MA. Intracranial meningiomas of atypical (WHO grade II) histology. J Neurooncol 2010;99(03): 393-405 